\title{
Navigating New Approaches for Grassroot Community Theatre in a (Post-)Covid World
}

\section{Kerrie READING}

\author{
Author: \\ Kerrie Reading \\ Cardiff Metropolitan University, UK \\ kreading@cardiffmet.ac.uk \\ https://orcid.org/0000-0002-4535-9960 \\ Date of reception: 20/02/2021 \\ Date of acceptance: $21 / 06 / 2021$ \\ Citation: \\ Reading, Kerrie. 2021. "Navigating New Approach- \\ es for Grassroot Community Theatre in a (Post)- \\ Covid World" Alicante Journal of English Studies \\ 35: 163-180. \\ https://doi.org/10.14198/raei.2021.35.08 \\ (C) 2021 Kerrie Reading \\ Licence: This work is licensed under a Creative \\ Commons Attribution 4.0 International License \\ (CC BY 4.0).

\section{(C) (1)}

\begin{abstract}
:
The cultural revolution of 1968 paved the way for many artists to reconsider how and where theatre was made. Community theatre gained currency and one company who became prominent during this cultural shift was Welfare State, later Welfare State International. They were one of the theatre companies who focused not only on a community theatre aesthetic but a grassroot one. I examine the radicality of community theatre and consider the efficacy of the historical approaches to engaging with communities in a (Post-)Covid world. I acknowledge and explore the shifting understanding of communities and assert that a deeper engagement is needed to foster collectivity (Tannahill 2016; Fişek 2019; Weston 2020; Bartley 2021). To reconsider the role that theatre may play in the future, I focus on a grassroot approach to community-led work and posit that location will be a key component to how theatre is made as we emerge from a pandemic.
\end{abstract}

Keywords: community theatre; grassroots; collectivity; locality 
The future of theatre is here. It's in our empty buildings, our streets, our parks and our houses. It's about things that matter to us, the stories that represent us and the things we want to talk about - on our terms. We are the message and the medium. We are the artists and the audiences. It starts with us (White 2020)

\section{Introduction}

Rhiannon White, one of two artistic directors of Common Wealth Theatre, draws our attention to what theatre could become after the global pandemic. White encourages us to consider our locality and she pushes us to think of ourselves. The simple inclusion of the word our suggests an ownership of space being at the heart of theatre - it is about people; it is about the stories we can tell from our own experiences and location. As I write this article, the pandemic continues to disrupt and halt live work, after, from March 2020 all theatres in the UK were forced to close their doors. The fallout of this meant mass unemployment or furloughed staff across the sector. For the first time in decades audiences have not been able to gather to watch live work and theatre companies are being forced to reconsider not only sources of income, but other ways of making and presenting their work.

This article looks towards community theatre and those working with the ideas of locality, collectivity and a grassroot approach. I posit that the three intertwined focusses are key for the direction of travel for theatre in a (Post-)Covid world. I look to these through examining a key shift in history, the post 1968 era, to suggest that this major turning point for artists could hold significance for those working in the sector today.

Firstly, this article addresses a historical understanding of community-based work with a lens into one of the pioneer groups of grassroot work: Welfare State International (hereafter WSI). It is clear how the location of their work became paramount, and I assert that locality is a key component to thinking about creating work today. Reflecting on the work of John McGrath, theatre maker and scholar Baz Kershaw writes how the idea of localism was a central part of his work with 7:84 Theatre and surmises that "[...] authenticating conventions should be drawn from the immediate socio-cultural environment of the performance" (1992, 154). I turn, therefore, to community theatre to rethink how theatre and its artists can find new ways of connecting to audiences through non-mainstream methods, particularly in a more localised, and politicized way that fosters collectivity. WSI decided to move to the Northwest of England in 1982 and settle in a community to make their work. They became part of the fabric of Ulverston and "in order to achieve that at a level which could be read without ambiguity 
and with some hope of making a significant impact on the culture of the locality, the company needed to become a local institution [...]" (Kershaw, 1997, 203). WSI offer an important historicity to community-based and grassroot work and their pioneering practices paved the way for community artists. The relationship between maker and audience was often blurred and the opportunity for coauthorship and participation in their work was paramount. I turn to WSI to understand how the company used community theatre approaches to connect with and interact with communities and generate work from the ground up.

Secondly, I draw on a more contemporary understanding of community theatre and look to issues such as collectivity and location to examine these within a time when people cannot gather. Writing on theatre, Jordan Tannahill acknowledges that ' $[\ldots]$ the theatre presents the world with a working model of cooperation, collectivity, and community' $(2016,37)$ and on discussing the idea of gathering and collectivity, theatre writer Emine Fişek says that "[...] collectives have been there from the start, as a way to trigger thinking not only around the idea of collectivity but also in the material form of an unwieldy mass of human bodies" $(2019,58)$.

Thirdly, in light of the above, I examine examples of community theatre today with a particular lens into the radical group Common Wealth Theatre and their lockdown performance Us, Here Now (2020) and some reflections on the long-running Women and Theatre and their filmed piece Women in Lockdown (2020). I am interested in the relationship between this pioneering company and the contemporary works discussed throughout this article to establish how the future of community theatre might look. It's an examination of influence from past approaches into a rapidly changing present. I assert that this approach is one way to navigate and repair community engagement and participation in a (Post-)Covid environment.

The two contemporary companies have both piloted different approaches to working during the lockdown period whilst remaining within a grassroot structure and therefore offer some radical new methods for working within and for communities. Common Wealth are based between Bradford and Cardiff, UK and Women and Theatre are based out of Birmingham, UK. During the period of the pandemic both companies have been continuing to work with their respective communities. Common Wealth have been looking to their specific locations as a means to collect and tell local stories. For the purposes of this article, I will be looking at the work they have carried out in Cardiff, where they have been considering how location specific stories could be viewed within a physical space. Women and Theatre have been focusing on collecting stories from women living in different areas across Birmingham and exploring how to use a digital platform to present these. 
This article, therefore, specifically addresses grassroot community theatre within a UK context to examine some of the practices being undertaken both from a historical standpoint and today. A short article addresses grassroot theatre, defining it as:

Grass is firmly anchored in the soil. Grassroots theatre derives its content, its subject matter, its message, its 'nourishment'-so to speak-from its own area. It is about things that are of special-and perhaps unique-concern to the people of its region. Unlike wheat and corn, grass is not grown for export. It feeds, beautifies and perhaps revitalizes the soil for future plantings. Nor is grassroots theatre for export. It is intended for a specific audience-the people of the locale or region in which it was developed. It is presented to the people from whose needs, values, tastes, problems, concerns interests it was 'grown' or developed (M. K. 1983, 2).

Whilst touring on a mass scale might not be possible for one time to come, I turn to companies engaged in local grassroots work to think about the future of theatre.

Whilst I appreciate that community theatre takes on other meanings across the globe, for the purposes of this article I remain within a British context, employing Steve Gooch's summation of the term. He explains how community theatre lies "[...] outside, and usually in opposition to, mainstream theatre, it responds to the concerns and serves the needs of the community which it is performed" (Gooch, 1984 in Chambers, 2002, 17). I explore how this understanding might allow a renavigation of grassroot approaches to community theatre making to create live work in a (Post-)Covid world. I am interested here in thinking about the efficacy and the shifting meaning of the term community, examining whether it is too much of a slippery term to revisit, or whether it holds value and legacy in the $21^{\text {st }}$ century.

Further still, this article examines how those working within community theatre have not only survived but explored new and radical approaches to engaging audiences during this shift in theatre ecology. Today, as we stand on the precipice of our own tipping point in history, we must discover how to approach (and continue) live theatre and perhaps rethink how and indeed where it is made and seen. Community theatre of the post-1968 era fell into the alternative/radical theatre scene and artists that engaged in creating this kind of theatre were critically examining the world in which they inhabited. Graham Murdoch outlined that the term radical drama: "sets out to present a critical perspective on the present social order. It aims to lay bare the structures of power and privilege and to show how they permeate everyday life, limiting and curtailing opportunities for self-realisation and social change" $(1980,151)$. Furthermore, Murdoch explores how "[...] radical drama attempts to link sympathy to struggle. As well as prompting people to reflect critically on the present situation, it aims to encourage them to take action to 
change it" $(1980,152)$. Kershaw remembers his own tour of alternative theatre in the 1970s and early 1980s and writes how some of those companies "[...] were mounting a radical critique of particular social and political policies. Nevertheless, all the companies identified themselves as part of a wider movement: the British 'alternative theatre movement'" $(1992,12)$. When Gooch first acknowledged the polarisation between the alternative and the mainstream in the 1980s, theatre had gone through a radical transformation and many artists had found new styles and venues in which to perform their work. The opposition he talks about is rooted in a major political shift and the post-pandemic world of theatre will most likely present a similar movement, or indeed a change in perspective. This enforced adjustment, I propose, is an important one for the landscape of theatre, it offers makers and audience the chance to reconsider the stories that are told, how they are told, and who they are told to.

\section{Some historical remarks on community theatre}

The revolution of 1968 (of which I will draw correlations and differences) saw many artists step away from London-centric theatre and from the established theatre building. Street theatre gained currency, as well as what came to be known as site-specific theatre. As British industry went into decline, many factories closed across the country and artists found disused spaces to become their sites of performance making and showing. Not only did they become sites of performance, but the former use became integral to the stories that emerged.

This period in history saw artists interested in exploring what theatre was beyond walls and how audiences engaged with that work. Theatre is known to reflect on and represent the world and that has once again reached a new tipping point. Steve Gooch remarked on theatre doing just this: "Theatre takes place within the physical and economic conditions of the world around it and is dependent on them for the material resources that make it happen. But theatre is also able to reflect and represent that world within itself" $(1984,17)$.

When examining the history of alternative/radical theatre, one cannot deny the enduring quality that performance offers, particularly when we look to the history of community theatre. Rhiannon White examines this from the lens of today, stating: "Culture at its best emerges when it needs to, reflecting back to us the world we live in. The best culture grows in the margins and especially grows in tough times, when artists need to speak" (White 2020).

In his manifesto that explored the notion of the alternative and community work, Steve Gooch wrote how "[t]he idea of theatre relating to, and being part of, the community from which it originates is neither new nor strange" (1984, 7). This is further explored by Emine Fişek in her recent account on Theatre 
\& Community: "[...] assemblies, crowds, masses and mobs are not modern phenomena; they are simply represented in new and distinct ways in the modern period" $(2019,58)$. Community theatre is a "[...] a term which implies the attempt to bring artefact and public closer together" (Gooch 1984, 7) and that has existed for a very long time and should not be seen as anything out of the ordinary.

Community theatre is one way in which to provide theatre to the public in a world where inside gathering may not be possible for some time to come. But it is more than simply a transference from the building to the outside. Kershaw reflects on the shift in theatre in 1968 and describes an event that Catherine Itzin called "one of the classic legendary events in political theatre" (Itzin, 1980b, 20 in Kershaw 1992, 115):

Muggins [...] opened at the London Unity Theatre on June 14, 1968, and was performed by actors from CAST and Unity Theatre. Albert Hunt and John Fox [...] were brought down from Bradford by Arden and D'Arcy to turn the approach to the theatre into an 'environment'. As well as foyer sideshows, the project finally included street performances, and improvised shows by local children instigated by D'Arcy. Simon Trussler sees it as an extension of Arden's community drama projects. [...] the occasion provided a kind of creative crucible, in which great cultural and ideological questions were addressed in the most concrete of terms, as an attempt was made to forge an efficacious relationship between overtly radical performance and the local community. Such ambitions, though, were bound to be shot through with the contradictions of the late 1960s (1992, 115).

The inherent politics involved in this reflection resonates with artists working within community theatre today. Reflecting on her experience of taking a circus to Gaza in 2010 following the Operation Cast Lead, Rhiannon White expresses that: "It taught me the value of culture and the need that we have as humans both to entertain and to be entertained. This was a first-hand experience of the power of play and imagination and of how transformational it can be for people and communities" (2020). Taking theatre and shows to people, and further still working with people to generate the work, not only allows theatre to become less elitist but it establishes relationships, opens a dialogue, and allows people to have a voice.

Community theatre has always been about connecting with and working alongside different groups of people. Much of the work that happened post 1968 attempted to bring theatre to the masses. However, on reflection this came with its own set of problems. There is the issue, as is discussed by Kershaw, about 
the danger of stereotyping and grouping people together for the purposes of an audience - he refers particularly to the work of John McGrath's with 7:84 Theatre. It was the case that McGrath employed 'popular' forms of theatrical conventions, such as "[...] concert parties, ceilidhs, the entertainments of contemporary working men's clubs" $(1992,153)$ for his audiences. McGrath believed that "[...] folklore and the popular arts could form the basis of counter-hegemonic cultural activism" and therefore serve its purpose as "[...] effective forms for use in radical theatre practice" (153). Kershaw, writing some years after the work of McGrath, reflects on this practice and discusses how this grouping of the working classes is a form of appropriation and that the stereotypes of the working classes are used to "[...] reinforce the status-quo" (154). McGrath, a socialist who weaved his political ideals into this theatre, was, as Kershaw outlines, aware of such dangers and acknowledged how working-class entertainments could be "[...] simplistic, racist, sexist, anti-working class, mindless, manipulative, trivial and nauseously ingratiating" (McGrath 1982b, 59-60 in Kershaw 1992, 154). But, as Kershaw goes on to discuss, the history of popular art forms is much more complex and does not simply, as McGrath seemed to assume, belong to the working classes. The attempt to adopt a particular kind of artform and claim that it is for a particular 'community of people' attempts to homogenise that group. Of course, we now acknowledge, appreciate, and celebrate the differences within communities. We can delve into theatre history and see how some theatre was created with the intention of being for particular groups of people, but as Fişek notes when discussing theatre for a gay community for example: "was 'the gay community' a unified entity? Or was it fractured by gender, race and class differences? Could it accommodate members who identified as queer?" $(2019,9)$. Sarah Weston echoes Fişek's concerns:

The existence of a project specifically aimed at an identity group surely presupposes some kind of commonality. Accordingly, the uncritical celeb ration of identity is no less problematic with groups of identity than with groups of locality: both are in danger of presenting a homogenous and essentialised account. The question I believe becomes to what extent does the principle of uniting a geographic community ignore or challenge social and cultural differences? (2020, 166).

There is of course still an efficacy of past community work due to its impact on theatre and how it has been experienced. Referring to Kershaw's experience of seeing a community play in Colyford, he describes how: "the staging makes you feel like you are part of something, rather than just looking at it". He describes the community play as a "community forming process, where theatre is created through community" $(1983,115)$. This is because the fundamental event is not 
just the play, "but the opportunity the play provides for the continuing evolution of Colyford as a community" (Kershaw 1983, 115).

Fişek focuses in on efficacy and states how the term "[...] can acquire different meanings depending on the stakes that one associates with the artwork" (2019, 18). She goes onto talk specifically about a 1999 production called Steelbound, performed in the working-class and former steel town of Bethlehem, Pennsylvania, USA. Touchstone Theatre's aim was to capture the town's memories and use these for a performance, however, Sara Brady, a theatre scholar writing on the performance argued that "[...] although company members had conducted extensive research and interviews with Bethlehem community members, professional theatre-makers had ultimately exercised control over the artistic product". Furthermore, Brady posited that the "[...] aesthetic agendas [...] reduced Steelbound's political efficacy and undermined its grassroots origins" $(2020,18)$. This performance was made in America, where the historical practices and understanding of community theatre differ slightly to the UK: "in the United States, the term refers to a strand of amateur theatre [...]" (Gooch 1984, in Chambers 2002, 171). However, it is worth acknowledging this production as a process that pushed a particular agenda on a community, rather than working with a community.

A company whose approach and ethos were rooted in the grassroot approach was WSI. Their approach, politics, and breadth of understanding when it came to making work within and for specific communities made them trailblazers of community-led work. WSI was set up in 1968 by John Fox and Sue Gill. Fox wrote how they attempted to "[...] find archetypes that are universally shared, and present them in an idiom accessible to a broad audience" $(1997,1)$. The idea of universality is now contested because it ignores historical and cultural milieu, however, at the time that WSI emerged, artists were really beginning to investigate the notion of a shared human experience ${ }^{1}$. Despite the blanket ethos about a collective human experience that today would be considered reductive and appropriative, WSI wanted to explore what it meant to be human and celebrate humanity through the use of myth, architype and stories.

WSI pioneered large-scale celebratory work across the UK and then globally, becoming Welfare State International in 1979. John Fox, writing on their work, includes their 1972 manifesto that described them as: "An Entertainment, an Alternative, a Way of Life. We make images, invent rituals, devise ceremonies, objectify the unpredictable and enhance atmospheres for particular places, times, situations and people. We are artists concerned with the survival and character of the imagination and the individual with a technologically advanced society" $(2002,3)$.

1 I am thinking particularly here of Richard Schechner, Peter Brook and Jerzy Grotowski. 
WSI engaged in works of varying scale. From audiences into their thousands to more ritualistic ceremonials, such as weddings or naming ceremonies that brought smaller communities together. Their work, regardless of scale, "[...] were part of a ferment of energy and experimentation that exploded from the late-sixties". Whilst many artists were pushing form and style in new avant-garde fashions, WSI were attempting a "[...] revitalising of traditional popular theatre forms" $(1997,6)$. In the early seventies they were invited by the Mid-Pennine Arts Association to take up residence in Burnley as their theatre fellow. Tony Coult writes how it had always been the aim of John Fox to "[...] work on the assumption that the company should teach people skills necessary to make their own celebrations, skills fast disappearing in a mechanised and de-skilled society" (8). The relationship between the company and the community in Burnley was not without its issues. There was a clash between cultures, with WSI appearing as 'hippies' in the circus-like area in which they set up camp, and the very 'progressive performances' that they put on, something that Fox admits they got wrong. But their years of experimentation, research, and their permanent relocation to Ulverston in the Northwest of England in 1982 permitted deeper relationships to be formed.

Kershaw reflects on the company's trajectory and posits that the move to Ulverston was indeed the most important shift in their work history. Their move to Ulverston allowed the company to embed into the community and draw on its rich history and landscape to inform their practices. This embedded approach allowed the company to foster relationships with the town and its people, and the sense of community was established through the works they created. This decentralisation of theatre was a key component to the radical shifts that occurred post 1968 and many artists were keen to move from the metropolis of London and make theatre elsewhere. I posit that artists today will be asking the questions about location and finding new ways to connect with, and build work with, local communities. Through their commitment, WSI became, as Kershaw states: "an anti-institutional institution" $(1997,202)$. Being embedded into the community allowed for works of varying scale to be produced and provided the company the time and the space to focus on annual traditions, such as the lantern parades that they successfully started and continue today.

It is worth noting that in 1999, Kershaw recognised that some of the largescale works they created would be considered as wasteful today due to the sheer number of resources they required. This shift is important to note and in the twenty-one years since Kershaw acknowledged this climate change and environmental concerns have grown exponentially. The work that Sue Gill and John Fox undertake today is rooted in the subjects of ecology and environment. It would not be sustainable or ethical to create a one-off community performance 
that would require so many resources, even if, as was the case with much of WSI's work, the materials are recycled. Kershaw also points out that: "The large numbers seem to generate excitement in their own right"; WSI "[...] were particularly influential in 1980s alternative theatre in large part because the scale of their projects almost guaranteed an impact on the community" $(1992,157)$. In thinking about community projects today and the parameters artists will be faced with, it is worth exploring and acknowledging the celebratory feel that can be established without the physical gathering of large-scale work.

Kershaw outlines the hopes of many artists creating work in the 1970s, stating that: "In attempting to forge new tools for cultural production, alternative theatre ultimately hoped, in concert with other oppositional institutions and formations, to re-fashion society" $(1992,22)$. If more alternative approaches to engaging with communities are established, then perhaps a post-pandemic society can also be refashioned in some way, one that puts the people at the heart of the questions being asked and the work that is created.

\section{Some reflections on contemporary community theatre}

Fişek explores the different notions of community and theatre, looking particularly at theorizing the terms from a European and American context. She identifies how the "[...] objectives can range from securing recognition for a community's particular experience to demanding public intervention on a topic of social or political concern to revitalizing the cultural life of a given locality" $(2019,14)$. Examining the British angle, Fişek refers to Kershaw's argument that places community theatre under the same umbrella as the alternative theatre movement that emerged in the 1970s. Fişek summaries how "references to community emerge in practices labelled popular or folk, grassroots or local, and socially engaged or protest theatre" $(2019,16)$. Despite the acknowledgement that community theatre exists alongside the more experimental theatre movement, Fişek does identify that today there is a danger in the former idea of 'community', in that it grouped people together and excluded others. She posits that " $[\ldots]$ theatrical community is never a given and that it is best approached as a problematic, or a question" $(2019,6)$.

Sarah Weston suggests that "theatre is produced through community, and simultaneously, community is formed through theatre: a temporal community that exists during the performance that has the potential to continue to affect the broader community that put the play on" $(2020,170)$. There is value to considering the idea of the formation of a community and the power of theatre to achieve this, and location allows for this to happen without the problematics of assumed identities or homogenisation. However, the concerns and acknowledgement of 
how the idea of community has changed over the last forty or so years is key to address. It would be foolish and ignorant to presume that a singular approach to engaging with and making community work could bring about collectivity. Fişek is also right then when she notes that "[t] he nostalgic idea of community can be used to support and even enhance, rather than undo, certain forms of social hierarchy" $(2019,9)$. This reinforces the idea that the approach to grassroot work is one that needs careful consideration and methodologies that ensure the participants involved are active agents of the work. Returning to Weston, she discusses the community play and the inherent politics involved. She draws the reader's attention to the Jellicoe approach of creating community theatre. ${ }^{2}$ Weston points out the potential problems of this model, outlining that: "[t]he use of a professional artistic team of playwright and director can be read as elitism, where the artist from outside of the community forces their artistic or political vision onto a community" $(2020,164)$. Looking to other models of community engagement in the theatre making process and assessing how this could be continued and built upon in a (Post-)Covid world is therefore crucial.

It remains imperative to look towards a theatre that is in opposition to the mainstream through a post-pandemic lens, one reason being is that simply looking at the traditional theatre building and the way they are set up, it becomes evident that they are not suitable for social distancing. This is highlighted in a recent Guardian newspaper article exploring the future of theatre buildings. John McAslan outlines how the theatres of the West End are "[...] completely outmoded. [...] People are four inches taller than when they were built, so the seats are too small, the sight lines are terrible and a huge number of seats are restricted by columns" (Wainwright 2020). Writing for The Stage, the theatre critic Lyn Gardner echoes the concerns I outline here: "I have no doubt that the theatre building will survive and, will have a vital role in giving work to artists and space to make shows. But it may be no bad thing if there's a shift in culture and in funding that means when we think of theatre, the mind's eye doesn't automatically think of a building" (2021). Discussing radical theatre, Kershaw acknowledges that "[c] ontemporary live performance, especially outside

2 This model is based on the playwright Ann Jellicoe: "Jellicoe's legacy in both professional and community theatre is significant, and perhaps her most noteworthy contribution was formalising a specific model of community theatre, the community play. Originating in Lyme Regis in 1978, Jellicoe's model has been replicated across the UK and internationally, with many prestigious political playwrights and theatre makers being part of the phenomenon, such as David Edgar, Howard Barker and Arnold Wesker. At the same time, the community play has been criticised in theatre literature and under-discussed in applied and community discourses and practices, despite its continued production and proven longevity" $(2020,161)$. 
theatre buildings, is a wonderfully energetic field to tap into [...] because as a profoundly public genre it is inevitably thoroughly contaminated by its wider cultural context" $(1999,7)$. The pandemic and its aftermath, therefore, invites us to reconsider how and where theatre is made and seen and perhaps broaden theatre's appeal to the wider public.

Sarah Bartley writes on the current austerity that the UK finds itself in and reflects on the notion of the "People's Theatre". She states that: "People's theatre occupy a hybrid position within arts practice that encompasses, both in form and organisational structure, amateur, community, and professional practices" (2021, 171). She goes onto to position this within the $21^{\text {st }}$ century, stating that "[...] this contemporary movement of people's theatres in the UK is defined by a set of spatial, economic, and inclusive practices which [...] are underpinned by radical modes of collectivity and grassroot civic participation" (2021, 171).

This recent exploration is key to address as Bartley situates this within a contemporary political landscape and explores what this could mean for, as she puts it, "socially committed performance" (171). Through the lens of The People's Theatre, Bartley posits that: "I illuminate the ways in which this model of performance making offers pathways to utilise collective action to reclaim discourses of resilience as a radical practice of empowerment within community theatre" (172). Collectivity, I posit, is crucial to post-pandemic theatre. We are living in, as Fişek remarks, a "[...] neoliberal culture [...] of individual selfsufficiency $[\ldots]$ " $(2019,48)$ and working within communities from the groundup will challenge the era of individualism. The current discourse surrounding radical and community theatre is therefore a timely issue that has currency with both artists and academics.

Bartley provides a case study on the theatre companies Slung Low, based in Leeds and Brighton's People's Theatre, both from the UK. Bartley reflects on their respective approaches and notes the methodologies of Brighton's People Theatre, focusing on their project The Open up Arts. This was an integrated research project that worked "[...] alongside councils, communities, academics, and other arts organisations" $(2021,179)$. Bartley continues, stating that the "[...] strand of work [...] illuminates the layered potential of peoples theatre practice to go far beyond the engagement of community members as participants in a performance and instead casts them as researchers, curators, designers, and producers [...]" (179-180). This approach, I would argue, is one that could be adopted in a world that must reconsider its cultural engagement.

There remain many forms and approaches to making community theatre that can be tapped into as we re-emerge from a theatrical lockdown. If people cannot gather in a building for some time to come, perhaps a revisitation of gathering outside for more street theatre, carnivalesque style of theatrical 
encounters could become popular again. Of course, mass gatherings do not always mean there is a shared meaning or ideology. It could just be "[...] a fleeting experience of collective proximity [...]" (Fişek, 2019, 47). Kershaw spoke how alternative, and community theatre was "[...] predicated on the potential power of the carnivalesque as an element of performance" $(1992,72)$. John McGrath supported the role of carnivalesque for a twentieth century theatre, expressing how: "[...] it is to this general area of celebratory, public, all-inclusive theatre that we should turn" (1990, 153-154 in Kershaw 1992, 71). Not since the turn of 1968 has there felt a more pertinent time to consider celebration and inclusivity to bring people together, but large-scale gatherings might not be the strongest route to take.

The pandemic has indeed pushed companies to reconsider the routes they take. Pentabus, the UK's leading rural touring company, have made a move to creating digitally focussed performances. Their latest piece includes Spring's Calling (2021), a collection of short audio pieces presented online that "focuses on nature, spring, outdoors, reflection, restarting and growth; as the cultural sector looks ahead to returning to live events, re-opening venues and welcoming back audiences" (Pentabus, 2021). A project from 2020 called Borderlands invited artists living on the border between England and Wales to create films for an interactive digital map. The resulting films were generated from the artists immersing themselves within the landscape, recalling memories and folk tales of their localities. Frozen Light, a theatre company specializing in creating interactive theatre shows for people with profound and multiple learning difficulties (PMLD), usually rely on making often inaccessible theatre spaces accessible for their audiences. During the pandemic they began reconsidering their direction and created a film called 2065: The Multi-Sensory Movie. To remain within their aesthetic, Frozen Light sent the audiences an interactive parcel ahead of the screening that was filled with sensory props connected to the story.

Pentabus, despite moving to the digital realm, have remained within a rural locality. Their engagement with the rural areas, particularly Shropshire where they are based, is key to their work. It is interesting how an online engagement can allow for a global reach and exploration and yet community-based companies are still using it to interact with and connect with their own localities. A grassroot approach encourages this engagement, as Sarah Weston posits, community plays "[...] presents the opportunity for simultaneous celebration and resistance" $(2020,164)$. Here I am reminded of Kershaw's description of a community play as a community forming process and White's reflection on the transformational qualities that theatre can have within communities. Talking about accessibility and theatre, Colette Conroy notes how: "Theatre requires that an audience gathers together to share an experience. For the time of the performance, we 
make a community of shared meaning. We are not required to think the same or to respond in the same way, but at the end of the evening we feel that we have experienced something together, across all our differences" $(2019,55)$. Whilst there may need to a be a deeper and more meaningful relationship nurtured for collectivity in community theatre, Conroy does bring our attention back to the essence of a theatrical encounter - as something shared, together.

\section{Common Wealth Theatre and Women and Theatre}

Rhiannon White writes how the "Covid-19 pandemic has unmasked deep fractures in society and the arts have not been spared, exposing elitism, racism and classism" (2020). White asks, expressing a need for change: could this "[...] be a time for radical imagination? For transformative ways for culture to be reimagined?" (2020). White also brings our attention to the government relief fund for Wales. She proposes that: 'We could share the $£ 53$ million by shifting power into the hands of people, artists, communities, nurturing new artists to take their place to tell the stories they need to tell" (2020). With such questions being asked by artists and projects being undertaken that ensure a meaningful relationship between artist and participant is fostered, community theatre companies are paving the way for how theatre could change. These considerations and relationships that are being established by leading companies will continue to be brought into question and grow as a result. White expresses that "[f] or Common Wealth, we are focusing on how we co-create and cocurate with our community. How do we find ways to reinvent making theatre, collectively, in empty spaces we want to reclaim? It'll involve working with a community sounding board, developing artists and bringing world-class theatre to the council estates of East Cardiff. On the community's terms" (2020).

The two artistic directors of Common Wealth Theatre both decided to live in their respective hometowns - Cardiff and Bradford. Much like WSI - they are rooted in these communities. Their connection to place is as important to them as it is to their participants, thus the sense of grassroots is both authentic and palpable to their work. What Common Wealth and Women and Theatre have in common is that they have been focusing on the immediate area in which they are based. This enables a relationship to be established and perhaps this focus provides a platform for different stories to emerge. These groups rely on the places in which they are situated as a fundamental component to the work that they create, and they draw upon not only the landscapes, or perhaps more fittingly, the cityscapes for their work, but perhaps more crucially, the people that occupy these spaces. Their stories and their responses to the work they create are at their heart. 
Common Wealth's work is about engaging smaller communities within a specific location, and they take the time for individual stories to emerge and be celebrated. Their recent piece, Us Here, Now (2020) documented people within East Cardiff. A photographer, Jon Pountney, captured people within the areas of St Mellon's, Llanrumney and Trowbridge. The aim of the piece was to challenge perceptions of the areas that have dominated since the 1970s when "[...] journalists [...] paid kids to vandalise a block of flats for a photoshoot and how the former Welsh Secretary of State demonised a generation by slating single mums and the future of their children" (Common Wealth Theatre 2021). Through shifting the narrative and documenting people, Common Wealth discovered an array of inspiring stories, humanising the area beyond the reputation unfairly imposed upon it. There was no mass gathering, no carnivalesque atmosphere, instead it was individual shots, displayed together, creating a sense of belonging and collective voices.

Us, Here Now, is a celebration of people, capturing individuals looking strong and proud. It documented their lives through photographs and culminated in an outdoors exhibition displayed within Cardiff and had an accompanying documentary film. The location was key to this piece of work but what was not able to happen, due the pandemic, was a gathering that brought the individuals together. However, the large display of photographs, and the documentary, pushes us to reconsider how events can be shared. Working outside of the theatre building is nothing new to Common Wealth Theatre, it is part of their ethos and they pride themselves on making accessible and political theatre. They have a DIY approach to theatre making that deliberately goes against the elitist theatre that charges inaccessible ticket prices to sit in a grand and traditional theatre. They describe themselves as a political, site-specific group, and they are paving the way for grassroot approaches to making theatre. For them it is about going to the communities that they want to work with and making the work there.

Women and Theatre have created Women in Lockdown, a filmed theatre piece that draws on women's experiences of the lockdown in 2020. Although the digital space, at first glance, offers a locationless platform, all the stories are derived from women in and around Birmingham and therefore the specificity of the location is crucial to the narratives that are communicated. There is a commonality in that all these women live within the same locality, yet they are unable to meet, and their stories all emerge from their own front rooms. The stories that emerge, albeit with crossovers of experiences, do not rely on a commonality other than the location. The assumption is not that the participants share the same socioeconomic background nor that they share the same experiences, other than the pandemic. Through engaging with the location in which they are based they can reach people who have a connection to that place and their story can 
become part of the narrative that is communicated through the project. The collaboration, sense of place, ownership and community is embedded into these projects during a global pandemic.

Women and Theatre have their roots firmly in Birmingham and the Black Country. Working outside of the theatre building is also part of their fabric. From watching Women in Lockdown and the identities of the women in the film, their sense of place becomes clear - through accents, through some shared experiences, and through the landscapes that emerge. The digital space provides a sense that it could be anywhere, but there is both a locationless and a locationess to the film. A sense of identity is shaped through the voices speaking because Women and Theatre made the choice to work with and gather stories from women in Birmingham. Therefore, the location is key to the outcome of their work.

The work that Common Wealth and Women and Theatre are doing and have done since they began, is rooted in people, place and the intrinsic link between the two. It is yet to be seen how both groups' grassroot work will develop, but place, and most importantly the people who occupy those places, is at the heart of their work. Considering this, I am particularly interested in Fişek's mention of community theatre's role to revitalize "[...] the cultural life of a given locality" but with the added "[...] demanding public intervention on a topic of social or political concern [...]" $(2019,14)$ because the two are so entwined and cannot, in the stark light of Covid times, be separated. Communities need to be revitalized but they need this revitalization to happen whilst at the same time demanding an intervention. Here is where a radical approach to theatre making could come into play.

\section{Conclusion}

Theatre artists working within the area of community theatre are experts at finding ways to tell human stories through the locality and fostering relationships with people. Historically, community artists have always responded to the world and found innovative ways of communicating and generating stories with communities of people. As we hear about the inevitable closure of prominent high street stores, it is yet to be known what will become of these spaces, but if history tells us anything, then artists and community groups will find ways to reclaim them.

The case studies I have drawn on through this article are discovering their own ways of not only representing the world but also commenting on it. Both Common Wealth and Women and Theatre have ensured that the work they have continued making during the pandemic remains about the people with whom they are creating with and the places in which they reside. The building has not needed to be a consideration. The grassroot methodology has firmly been part 
of the process and the outcome of the work produced. As Gooch reminds us: "Talking about art isn't the same as doing it, and just as theatre may reflect on the world but doesn't act on it, so comments from outside the theatre which reflect on its practice remain mere comment until turned into production" $(1984,18)$.

The pandemic has pushed much of theatre into the digital realm and yet community artists have carved out methods that still ensure a meaningful relationship is being fostered. Pentabus, Frozen Light and Women and Theatre have used the audio and filmic techniques to consider their direction, and yet all of them have ensured that participants remain the focus of the creation process and/ or the experience of the piece. The location for both Pentabus and Women and Theatre, despite the digital platform, remains at the heart of their work and this, in turn, aids the relationship that is built with their audiences and participants.

Common Wealth Theatre, much like WSI, are rooted in their cities in which they grew up in and know. They are determined to make theatre more accessible and bring people in to be at the heart of their own stories. Unlike the others, they do not rely on the digital realm, they are striving to find ways of working physically with people as much as possible.

WSI paved the way for many community artists, offering a different approach to theatre making that put the participant and locality at the heart. Their grassroots approach to generating work offers an important landmark in theatre history, yet the large-scale and carnivalesque performances may not be the way to think about community cohesion.

Companies like Common Wealth Theatre and Women and Theatre, amongst many more, are always finding new ways to connect with people and whilst they acknowledge and draw on the fact that the struggle or experiences are not necessarily shared, the goal often is. We must acknowledge key shifts in our understanding of 'communities', but through this, we can also focus on locality and a grassroots approach to nurture collectivity.

\section{Works cited}

Bartley, Sarah. 2021. "UK People's Theatres: performing civic functions in a time of austerity." Research in Drama Education: The Journal of Applied Theatre and Performance 26(1): 171-186. https://doi.org/10.1080/13569783.2020.1853516

BleEKer, Maaike, Adrian Kear, Joe Kelleher and Heike Roms, eds. 2019. Thinking Through Theatre and Performance. London: Bloomsbury.

Conroy, Colette. 2019. "How can the theatre be fully accessible?" In Bleeker, Kear, Kelleher and Roms 2019.

Coult, Tony and Baz Kershaw. 1983. Engineers of the Imagination: The Welfare State Handbook. London: Methuen. 
FIșEK, Emine. 2019. Theatre and Community. Palgrave Macmillan, UK.

Fox, John. 2002. Eyes on Stalks. London: Methuen.

GARDNER, Lyn. 2020. "Is it time to think differently about theatre buildings?" The

Stage. Available at: https://www.thestage.co.uk/opinion/theatre-buildings-willsurvive-but-we-have-to-use-space-differently [accessed 15 February 2021]

Gooch, Steve. 1984. All Together Now: An Alternative View of Theatre and The Community. London: Methuen.

Kershaw, Baz. 1992. The Politics of Performance: Radical Theatre as Cultural Intervention. London: Routledge.

Murdoch, Graham. 1980. "Radical drama, radical theatre." Media Culture E Society 2 (2):151-168. https://doi.org/10.1177/016344378000200204

M.K. 1983 "Grassroots Theatre: An Introduction." The Drama Review: TDR, Summer, Vol. 27, No. 2, p. 2

TANnAHILl, Jordan. 2016. "Why Live?: A Question for 21st Century Theatre." World Literature Today 90 (1): 36-39. https://doi.org/10.7588/worllitetoda.90.1.0036

Weston, Sarah. 2020. "Being part of something much bigger than self': the community play as a model of implicit and explicit political theatre practice." Research in Drama Education: The Journal of Applied Theatre and Performance 25 (2):161-177. https://doi.org/10.1080/13569783.2019.1692653

White, Rhiannon. 2020. "The future of theatre is here." Institute of Welsh Affairs. Available at https:/www.iwa.wales/agenda/2020/07/the-future-of-theatre-ishere/ [accessed 29 January 2021].

Wainwright, Oliver. 2020. "What's the future of theatre? A Scottish seaside town may have all the answers." Available at https://www.theguardian.com/ artanddesign/2020/jul/14/covid-future-theatre-scottish-seaside-town-answersdunoon [accessed 14 January 2021].

\section{Websites consulted}

www.commonwealththeatre.co.uk [accessed $18^{\text {th }}$ March and 30 $0^{\text {th }}$ May 2021]

https://www.frozenlighttheatre.com [accessed 30 $0^{\text {th }}$ June 2021]

https://www.pentabus.co.uk [accessed 30 ${ }^{\text {th }}$ June 2021]

www.womenandtheatre.co.uk [accessed $18^{\text {th }}$ March and 30 ${ }^{\text {th }}$ May 2021] 